\title{
Does the Future of Food Pass by Using Nanotechnologies?
}

\author{
Miguel Ângelo Cerqueira* and Lorenzo Miguel Pastrana* \\ International Iberian Nanotechnology Laboratory, Braga, Portugal
}

Keywords: nanotechnology, nutrition, nanomaterials, nanoparticles, food quality, food safety

\section{INTRODUCTION}

The food system, as a whole, is facing a series of paramount challenges for this century, namely:

- The demographic growth; the world population increases 1\% each year (from 7.8 billion in 2019 to an expected number of 8.6 billion in 2030) (Worldometers, 2019) and thus being needed more food to feed the world's population;

- The urbanization; the world's population residing in urban areas in the period of 2014 to 2050 will increase from 54 to $66 \%$, respectively (UN DESA, 2014), which will have a great impact on the food distribution systems;

- The aging; is expected that by 2030 more than 1 billion people will be aged 65 or older that represents an increase from $\sim 8$ to $13 \%$ from the period of 2019 to 2030 (NIA, 2007), demanding for foods with new textural aspects and nutritional requirements;

OPEN ACCESS

Edited by:

Maria Jose Sousa-Gallagher, University College Cork, Ireland

Reviewed by: Kashub Steven Tumwesigye, National Agricultural Research Organisation, Uganda

*Correspondence: Miguel Ângelo Cerqueira miguel.cerqueira@inl.int Lorenzo Miguel Pastrana lorenzo.pastrana@inl.int

Specialty section:

This article was submitted to Sustainable Food Processing, a section of the journal Frontiers in Sustainable Food Systems

Received: 27 October 2018 Accepted: 28 February 2019 Published: 26 March 2019

Citation: Cerqueira MÂ and Pastrana LM (2019) Does the Future of Food Pass by Using Nanotechnologies? Front. Sustain. Food Syst. 3:16. doi: 10.3389/fsufs.2019.00016
- The sustainability; is expected that the $\mathrm{CO}_{2}$ emissions continue increasing in the next years, but there is a great pressure to reduce the agriculture impact (UNEP, 2017) and therefore more sustainable raw materials and efficient technologies are needed;

- The climate change; is forecast that the overall temperature increase could go up to $5^{\circ} \mathrm{C}$ during the next century (NASA, 2019), which will stress the agriculture sector by changing the growing of crops, the way that animals are raised and the fishing sector.

These challenges raise up important issues and questions that need to be solved, for instance: 800 millions of people are hungry in the world nowadays. Food and Agriculture Organization of the United Nations (FAO) estimates that every year around the globe 1.3 billion tons of food is lost or wasted, representing $1 / 3$ of all food produced for human consumption (Food and Agriculture Organization, 2009). In combination with the environment impact of food chain (e.g., production and shipping), the sustainability rises as one of the challenges of the food system. At the same time in the first world obesity, diabetes, hypertension are reaching to epidemic levels, for which health organizations have alerted about their impact on the public health, and thousands of people die every year due to preventable foodborne diseases around the world (World Health Organization (WHO), 2015). Moreover, it is estimated that by 2050 world population will require $100 \%$ more foods and the current food production technologies will not be enough to satisfy the increasing food demand, also promoted by the decrease of production by the traditional resources (i.e., small and family-runs farms). For that reason, it is expected that by 2050 seven out of $10 \mathrm{~kg}$ of foods produced should be from new and improved technologies (Food and Agriculture Organization, 2009).

The above issues support the need for a new sustainable food system where traditional food production technologies have to be replaced or complemented with applications made with new disruptive technologies. Key enable technologies (KET: biotechnology, nanotechnology, and Information and Communications Technology) are the main candidates to play a significant role in this change. It is expected that the nanotechnology market for food industry increases from 7 billion US dollars in 2015 to 20.4 billion US dollar in 2020 (Cerqueira and Pastrana, 2017). 
This is why academic, industry and government have to build public trust in a strong, credible international oversight process explaining the advantages of products containing nanotechnology. This can be done through the media or during public events in which true examples and friendly language communication are used. During communication is important to show how nanotechnology is used and applied and how is guaranteed the safety during the development and production of nanotechnology-based products. One of the good examples has been the outreach supported by the International Iberian Nanotechnology Laboratory (Portugal), through the promotion of nanotechnology in different fields (in which food area is having a great expression). This can also be done using examples already in the market where can be highlighted the aeronautics (e.g., nanocomposites lighter and with improved mechanical properties) and health areas (e.g., nano-delivery systems with specific targets), as good examples of the actual use of nanotechnologies in the daily life.

The main advantages of using nanotechnology against micro and macrosized systems and technologies will depend on the area of application and specific product. But normally, nanoscale exhibits physical and chemical properties that are substantially different from the micro and macroscale, and which are often related with their large surface area-to-volume ratio.

The future of new food systems should be oriented in two main axes: the food chain and consumers (Institute of Medicine (US) Food Forum, 2009). In the food chain ax nanotechnology will provide different solutions in the production of raw materials, processing and packaging. In the same way, in the consumer ax nanotechnology will play a role in the body and gut health and function but also in the sensorial perception and pleasure at mouth and brain level (Figure 1).

In the next sections, five of the priority solutions for both axes are presented and discussed based on the use of nanotechnologies.

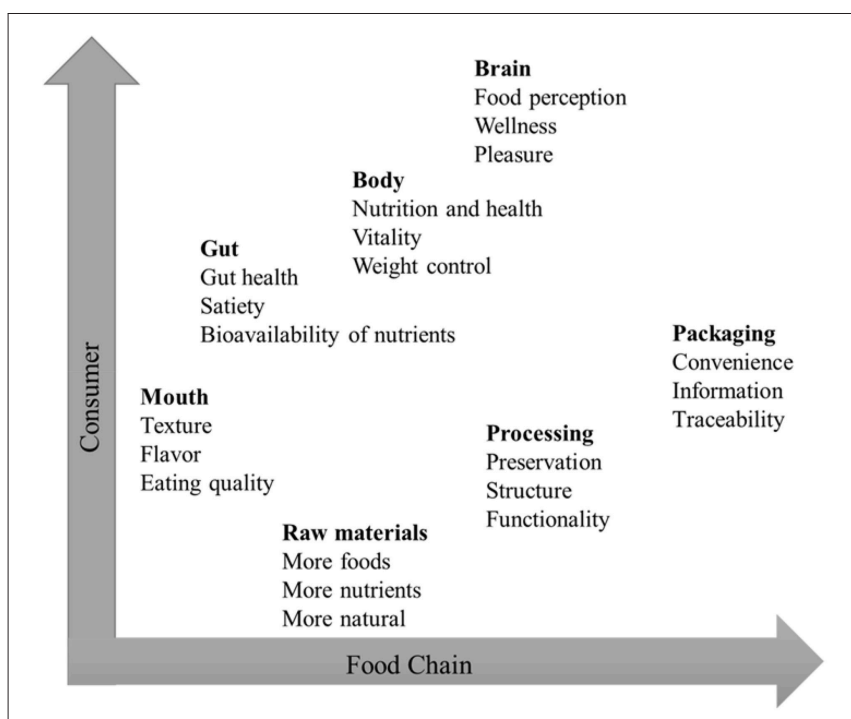

FIGURE 1 | Axes of food systems where nanotechnology will have impact.

\section{FOOD NANOSTRUCTURES}

The unique characteristics of foods came not only from their chemical composition but also from their micro and nanostructure. The occurrence in nature of a particular structure at nanoscale of the food ingredients (mainly polymers: proteins, carbohydrates and lipids) determines the properties and technological aptitude of foods. For example, milk is a nanostructured food. In milk, casein is naturally present forming micelles and is responsible for the high stability of lipids in milk (Martin et al., 2007). It would be simplistic trying to explain the variety of cheeses and fermented milk products taking only into account the very slight differences in their composition. Micro and nanostructure of the diverse dairy products are the main responsible for the huge differences in their organoleptic properties. Also, during the digestion most of the consumed foods are broken-down in small structures and in the end molecules that are absorbed or eliminated. Some of the examples are fibers with nanosized crystalline structures or micelles which are naturally formed in the gut. This deconstruction process happens naturally bring macroscopic structures (i.e., foods) to the nanoscale, and is necessary for the proper nutrient absorption.

Nanoscale in food structures can lead to higher surface area, distinct optical behavior, chemical and kinetic stability, and low density vs. high mechanical properties. These possibilities, can lead to several advantages in food processing operations such as: improved solubility and bioavailability of bioactive compounds, and better sensorial behavior, once can be used to prevent undesirable chemical reactions and protect functional compounds against chemical degradation as well as avoid the compatibility problems between ingredients and the food matrix (Cerqueira et al., 2017b). In fact, in this particular case several solutions have been presented in the last 2 decades years by the use of high-energy and low energy methods. Some of the interesting approaches are the use of $\mathrm{pH}$, temperature or ionic driven methodologies for the creation of new nanostructures in raw materials, and thus controlling organoleptic properties (i.e., texture). The formation of nanofibrils using milk proteins (Fuciños et al., 2017) or nanostructured crystals using waxes or monoglycerides (Martins et al., 2016; Cerqueira et al., 2017a) are some of the examples of structures that can be used to change food characteristics.

During food processing there are several advantages on using nanostructured devices aiming to increase the efficiency and selectivity of the processes. One of the examples are nanostructured membranes with high surface area which can be used for filtration or immobilization of enzymes; they can be used to improve efficiency and stability, and then reused to reduce the process cost.

During processing, nanoencapsulation can also be used to mask off-flavors or enhance the color in foods. One of the examples is the encapsulation of poly-unsaturated fatty acids, in which rancidity during the processing or cooking can be avoided. 


\section{MORE HEALTHY AND FUNCTIONAL FOODS}

Nanotechnology allows enhancing the efficacy and the nutrition value of food ingredients by increasing the stability and bioavailability of bioactive food ingredients. By using nanoencapsulation technologies degradation of labile compounds such as vitamins and antioxidants, can be diminished. These technologies can also be used to deliver functional compounds on-demand to customer's health requirements increasing their bioavailability by enhancing the absorption in the human gut with a controlled release pattern (Cerqueira et al., 2014). That opens the possibility to establish personalized nutrition schemes and allow consumers to safely choose food products based on their best interests.

Nanoencapsulation technologies can be divided by topdown and bottom-up. Among bottom-up nanoprecipitation, coacervation, emulsion diffusion, and emulsion coacervation are the most used methods. Among top-down high-pressure homogenization and ultrasounds are the conventional used for the production of nanoemulsions. But in the last 10 years, two nanoencapsulation methods arise: nanospray-drier and electrohydrodynamic processing. Nanospray-dryer is derived from the conventional and well-established spray drying technology that has been commonly used for improving product preservation in dried solid form, and can be used with a broad range of biopolymeric materials. The nanospraydryer uses a vibrational atomization systems and electrostatic collector for the formation of the particles and their collection, respectively. The nature of the wall material used (chemical structure and intrinsic molecule charge) and its concentration in solution have a strong influence on the size and standard deviation of the particles. However, the attempts to extend this technology to food has been hard due the difficulties to scaleup the process. Other of the emerging methodologies is the electrohydrodynamic processing. It has been recently proposed as a simple and straightforward method to produce submicron encapsulation structures from a great variety of materials. Multiple morphologies can be made, and continuous polymeric fibers and capsules can be obtained. Due to their small surface areas and small pore size the electrospun and electrosprayed materials are excellent candidates for creating small droplets of solid or liquid particles (core material) which are packed into a matrix (wall material) in comparison with other processed nanomaterials. Other of the advantages is the capacity to produce and dry the particles without using temperature, which could be helpful during the processing of termolable compounds (Costa et al., 2018).

Several compounds have been encapsulated using these technologies, and there are several scientific publication showing the possibility of encapsulate vitamins, mineral, phenolic extracts, essential oils, colorantes, etc., using these methodologies, but only few show the advantages of being nanoencapsulated (Li et al., 2015; Silva et al., 2019). For that is important the use of in vitro and in vivo methods to demonstrate the advantages of using these nanostructures.

\section{FOOD PACKAGING}

Probably, is on packaging that nanotechnology is most accepted and extended used in the food sector. This is explained by the clear advantages such as the improvement of the materials properties (barrier, mechanical, light materials) and their use in the development of active and intelligent packaging systems. Besides the incorporation of nanostructures (e.g., nanoclays, silver nanoparticles) also the development of nanomultilayers have been shown several advantages (Cerqueira et al., 2018a) in the final properties of packaging materials. They can help companies in reducing permeabilities to oxygen and water vapor and to improve the mechanical properties of the packaging and thus achieve characteristics that were impossible some years ago.

Nanocomposites based on graphene nanoplate, carbon nanotubes, and nanoclays are reported to improve the heat resistance and the gas barrier properties, mainly in the case of plastics made with biodegradable polymers (Ramanathan et al., 2008), while in the particular case of active packaging are the scavenging and antimicrobial capacity the one that was most explored. Active packaging has been used to extend shelf-life of foods (e.g., fresh meat, poultry, and fish) reducing rancidity and microbiological growth during storage. These packaging solutions are based on the incorporation of the plastic matrix nanoparticles materials such as zinc oxide and silver that due to their nanosized and unique properties are able to act against a broad spectrum of microorganisms (Mihindukulasuriya and Lim, 2014).

Intelligent food packaging is another field of application of nanotechnology merging food contact materials with sensors (next section will explore this particular application). Intelligent food packaging can monitor and indicate the quality and safety of the food through the food chain by using RFID (radiofrequency identification) tags and indicators that can be used to inform about the safety or freshness of the packed food products, and DNA and antibody-based sensors with the capacity to detect growth of pathogen bacteria and thus informing their presence. In addition, intelligent packaging can be used for food authenticity purposes and for tracking the history during the shipping and storage (packaging integrity, temperature, or expiration date).

Food packaging is without any doubt the most mature field of nanotechnology application in foods and several companies are already selling these nanotechnology-based products, such as Nanocor, Polyone, Kinetic, Always Fresh, FresherLonger, and Valetins Nanotech (Cerqueira et al., 2018b).

\section{NANOSENSORS}

Food sensors based on nanotechnology are one of the most promising uses of nanotechnology in the food industry. They can be used to measure low amounts of several compounds that can help in controlling the safety and quality of food products in a reduced period of time (Vanderroost et al., 2014). Thus, several sensors based on chemical and biological reactions have been produced. They have been used to detect 
and measure the presence of chemicals (e.g., toxins, volatiles, allergens) and bacteria (e.g., Listeria monocytogenes). Different nanotechnologies are behind these sensors, for instance, resonance cantilever that change the resonance frequency as a function of the increasing mass, superficial tension, temperature, or molecular recognition. Also, functionalized plasmonic nanoparticles could be used to recognize a large number of small molecules, large proteins, and macromolecules. The use of these nanomaterials for food DNA analysis has the potential of providing increased sensitivity, multiplexing capabilities, and reduced costs. For example, gold NPs (AuNPs), and gold nanorods (AuNRs) are being used for DNA detection taking advantage of their optical properties. Combination of these particles with molecular biology techniques such as LoopMediated Isothermal Amplification (LAMP), or Recombinase Polymerase Amplification (RPA), allow making faster, reliable and affordable food analysis based on DNA.

Nanotechnology can also be present in sample preparation during food analysis, overcoming some of the limitations associated with food analysis by the development of tailored, miniaturized, automatized and faster sample preparation techniques based on microfluidics (Garrido-Maestu et al., 2018).

\section{FOOD SENSATIONS}

In the last end of twentieth century, the molecular gastronomy concept was developed to give a scientific and engineering view of the process involved in the gastronomic food preparations. Some kitchens became labs by using scientific instrumentation and drying, liquefying, gassing, and freezing were applied to obtain new food properties, structures, textures, and sensations (Sanguansri and Augustin, 2006).

More recently nanotechnology joined molecular gastronomy for producing nanostructures with fewer defects, more homogenous chemical composition, and better short- and longrange ordering by means a bottom-up approach manipulating individual atoms and molecules able to self-assemble in a natural and self-regulating manner. In this context, 3D printed food arise, joining the machinery engineering and food ingredients. $3 \mathrm{D}$ printed food is the most promissory industrial application of this approach. New food and culinary experiences can be created through the deposition and structuration of edible polymer fibers and particles. 3D food printing technology can also be used for target population needing special foods (e.g., elderly people) due to physiological dysfunctions (e.g., dysphagia) and specific nutritional requirements (e.g., protein, iron, and calcium) (Aguilera and Park, 2016).

\section{REFERENCES}

Aguilera, J. M., and Park, D. J. (2016). Texture-modified foods for the elderly: Status, technology and opportunities. Trends Food Sci. Technol. 57, 156-164. doi: 10.1016/j.tifs.2016.10.001

Cerqueira, M., and Pastrana, L. (2017). Nanotechnology in the Food Industry: 'plenty of room' to Innovate. New Food Magazine. Available online at: https:// www.newfoodmagazine.com/article/42338/nanotechnology-food-industryplenty-room-innovate/

\section{FINAL REMARKS}

The study of food structure at the nanoscale is one of the emerging topics in the nanotechnology world, and if some years ago it seems impossible today is a reality to evaluate the food structure and develop new food grade systems at the nanoscale. This is changing the way that scientists and companies are looking to food structure and the way that several processes have been reused in the food industry. In fact, the increasing number of publications and patents are an evidence of the fast growth of this interest. And despite some market studies mention that the number of companies focusing their research and development on nanotechnology-based products is increasing, being between 1,000 and 2,000, only a few are focused in food applications (HKC, 2015; Nanowerk, 2018). This low investment is mostly related to the cost, the regulatory aspects, and the consumer behavior, which are putting several barriers to the companies that are interested in using nanotechnology in their products.

In the particular case of companies and consumers should be promoted among the stakeholders a scientific awareness of the real risks of using nanotechnologies in food applications. Governmental organizations, academia, and industry should work together to show the consumers the advantages and safety of using nanotechnology in food products and thus increase the acceptance of nanotechnology-based products. In our opinion scientists and researcher, from both public and private institutions, have an important role on this; they are present since the beginning, and once they are responsible in most of the times by the conception, developing and evaluation of the technologies, they should always evaluate the way they share and show their results. The way that we communicate new breakthroughs in science will be responsible for more enthusiastic and conscientious end users, such as companies and consumers, respectively.

\section{AUTHOR CONTRIBUTIONS}

The authors MC and LP contributed to conception, design, writing, and revision of the manuscript. All authors read and approved the submitted version of the manuscript.

\section{ACKNOWLEDGMENTS}

We would like to acknowledge the H2020-MSCA-RISE project FODIAC-Food for Diabetes and Cognition (reference number 778388).

Cerqueira, M. A., Fasolin, L. H., Picone, C. S. F., Pastrana, L. M., Cunha, R. L., and Vicente, A. A. (2017a). Structural and mechanical properties of organogels: role of oil and gelator molecular structure. Food Res. Int. 96, 161-170. doi: 10.1016/j.foodres.2017. 03.021

Cerqueira, M. A., Pinheiro, A. C., Ramos, O. L., Silva, H., Bourbon, A. I., and Vicente, A. A. (2017b). "Advances in food nanotechnology," in Micro and Nano Technologies, ed R. Busquets (Boston,MA: Elsevier; Emerging Nanotechnologies in Food Science), 11-38. 
Cerqueira, M. A., Pinheiro, A. C., Silva, H. D., Ramos, P. E., Azevedo, M. A., Flores-López, M. L., et al. (2014). Design of bio-nanosystems for oral delivery of functional compounds. Food Eng. Rev. 6, 1-19. doi: 10.1007/s12393-0139074-3

Cerqueira, M. A., Torres-Gines, S., and Lagaron, J. M. (2018a). "Nanostructured multilayer films," in: Nanomaterials for Food Packaging: Materials, Processing Technologies, and Safety Issues, 1st Edn, ed M. A. Cerqueira, L. M. Pastrana, J. M. Lagaron, A. A. Vicente (Amsterdam: Elsevier), 147-171.

Cerqueira, M. A., Vicente, A. A., and Pastrana, L. M. (2018b). "Nanotechnology in food packaging: opportunities and challenges," in: Nanomaterials for Food Packaging: Materials, Processing Technologies, and Safety Issues, 1st Edn, M. A. Cerqueira, L. M. Pastrana, J. M. Lagaron, A. A. Vicente (Amsterdam: Elsevier), 1-11.

Costa, M. A., Ramos, P. E., Fuciños, P., Teixeira, J. A., Pastrana, L. M., and Cerqueira, M. A. (2018). "Development of bio-based nanostructured systems by electrohydrodynamic processes," in: Nanotechnology Applications in the Food Industry, eds V. R. Rai and J. A. Bai (Boca Raton, FL: CRC Press Taylor \& Francis Group), 3-20.

Food and Agriculture Organization (2009). How to Feed the World in 2050. Available online at: http://www.fao.org/fileadmin/templates/wsfs/docs/expert paper/How_to_Feed_the_World_in_2050.pdf (accessed February 10, 2019).

Fuciños, C., Míguez, M., Fuciños, P., Pastrana, L. M., Rúa, M. L., and Vicente, A. A. (2017). Creating functional nanostructures: encapsulation of caffeine into $\alpha$-lactalbumin nanotubes. Innov. Food Sci. Emerg. Technol. 40, 10-17. doi: 10.1016/j.ifset.2016.07.030

Garrido-Maestu, A., Azinheiro, S., Carvalho, J., and Prado, M. (2018). Rapid and sensitive detection of viable Listeria monocytogenes in food products by a filtration-based protocol and qPCR. Food Microbiol. 73, 254-263. doi: $10.1016 /$ j.fm.2018.02.004

HKC (2015). Helmut Kaiser Consultancy. Study: Nanotechnology in Food and Food Processing Industry Wordwide. 2008-2010-2015. Available online at: http:// www.hkc22.com/Nanofood.html (accessed February 10, 2019).

Institute of Medicine (US) Food Forum (2009). "Nanotechnology in food products: workshop summary," in Application of Nanotechnology to Food Products (Washington, DC: National Academies Press. Available online at: https://www. ncbi.nlm.nih.gov/books/NBK32727/.

Li, Z., Jiang, H., Xu, C., and Gu, L. (2015). A review: using nanoparticles to enhance absorption and bioavailability of phenolic phytochemicals. Food Hydrocoll. 43, 153-164. doi: 10.1016/j.foodhyd.2014.05.010

Martin, G. J., Williams, R. P., and Dunstan, D. E. (2007). Comparison of casein micelles in raw and reconstituted skim milk. J. Dairy Sci. 90, 4543-4551. doi: $10.3168 /$ jds.2007-0166

Martins, A. J., Cerqueira, M. A., Fasolin, L., Cunha, R. L., and Vicente, A. A. (2016). Beeswax organogels: influence of gelator concentration and oil type in the gelation process. Food Res. Int. 84,170-179. doi: 10.1016/j.foodres. 2016.03.035
Mihindukulasuriya, S. D. F., and Lim, L. T. (2014). Nanotechnology development in food packaging: a review. Trends Food Sci. Technol. 40, 149-167. doi: 10.1016/j.tifs.2014.09.009

Nanowerk (2018). Available online at: https://www.nanowerk.com/ nanotechnology/research/nanotechnology_links.php.

NASA (2019). National Aeronautics and Space Administration. Available online at: https://climate.nasa.gov/ (accessed February 10, 2019).

NIA (2007). National Institute on Aging (U.S. Department of Health and Human Services), Why Population Aging Matters: A Global Perspective. Available online at: https://www.nia.nih.gov/sites/default/files/2017-06/WPAM.pdf (accessed February 10, 2019).

Ramanathan, T., Abdala, A. A., Stankovich, S., Dikin, D. A., Herrera-Alonso, M., Piner, R. D., et al. (2008). Functionalized graphene sheets for polymer nanocomposites. Nat. Nanotechnol. 3, 327-331. doi: 10.1038/nnano.2008.96

Sanguansri, P., and Augustin, M. A. (2006). Nanoscale materials development: a food industry perspective. Trends Food Sci. Technolol. 17, 547-556. doi: 10.1016/j.tifs.2006.04.010

Silva, H. D., Beldíková, E., Poejo, J., Abrunhosa, L., Serra, A. T., Duarte, C. M. M., et al. (2019). Evaluating the effect of chitosan layer on bioaccessibility and cellular uptake of curcumin nanoemulsions. J. Food Eng. 243, 89-100. doi: 10.1016/j.jfoodeng.2018.09.007

UN DESA (2014). United Nations Department of Economic and Social Affairs, 2014 Revision of World Urbanization Prospects. Available online at: https://esa.un. org/unpd/wup/publications/files/wup2014-highlights.pdf (accessed February 10, 2019).

UNEP (2017). The Emissions Gap Report 2017. United Nations Environment Programme (UNEP), Nairobi. Available online at: www.unenvironment.org/ resources/emissions-gap-report (accessed February 10, 2019).

Vanderroost, M., Ragaert, P., Devlieghere, F., and De Meulenaer, B. (2014). Intelligent food packaging: the next generation. Trends Food Sci. Technol. 39, 47-62. doi: 10.1016/j.tifs.2014.06.009

World Health Organization (WHO) (2015). Available online at: http://www.who. int/foodsafety/areas_work/foodborne-diseases/ferg/en/ (Accessed September 20, 2018).

Worldometers (2019). Available online at: http://www.worldometers.info/worldpopulation/world-population-projections/ (Accessed February 20, 2019).

Conflict of Interest Statement: The authors declare that the research was conducted in the absence of any commercial or financial relationships that could be construed as a potential conflict of interest.

Copyright (C) 2019 Cerqueira and Pastrana. This is an open-access article distributed under the terms of the Creative Commons Attribution License (CC BY). The use, distribution or reproduction in other forums is permitted, provided the original author(s) and the copyright owner(s) are credited and that the original publication in this journal is cited, in accordance with accepted academic practice. No use, distribution or reproduction is permitted which does not comply with these terms. 